\title{
Bulk Soil Properties as Determinants of the Compression Strength of Puddled Lowland Paddy Soils in Sri Lanka
}

\author{
G.V.T.V. Weerasooriya* , D.N. Jayatissa ${ }^{1}$ and M. Rambanda ${ }^{2}$ \\ Postgraduate Institute of Agriculture \\ University of Peradeniya \\ Peradeniya
}

\begin{abstract}
Soil strength/penetration resistance of lowland puddled soil is an important parameter for designing farm machinery. This study was aimed to estimate the overall penetration resistance of lowland puddled soils through the assessment of bulk soil parameters. Penetration resistance and bulk soil parameters including moisture content, bulk density, particle density, porosity, texture and organic matter content were measured under real field condition and evaluated to identify the suitable determinants to explain the variation of soil penetration resistance and their relationships. Results revealed that measured penetration resistance by Eijkelkamp hand penetrometer and bulk soil parameters except particle density, notably varied with weed controlling methods, depth of the soil and the time. Penetration resistance showed a significant relationship with bulk density (BD), moisture content $(M C)$ and porosity $(P O)$ at $.05 \alpha$ level as using the relationships 4017.8744.72 MC-1669.83 BD, 2115.65-44.18 PO and 3383.78-58.09 PO in $0-10 \mathrm{~cm}, 10-20 \mathrm{~cm}$ and $20-30 \mathrm{~cm}$ depths, respectively.
\end{abstract}

Keyword: Bulk soil parameters, penetration resistance, soil strength, weed controlling methods

\section{INTRODUCTION}

The soil-crop-machinery interaction studies give paramount importance in providing design parameters such as soil strength which is useful to determine the workability of farm machinery (IRRI, 1994), draft (Lipiec and Hatano, 2003) and power requirements (Hillel, 2004 ) etc. Soil strength is defined as the capacity of a soil to resist or endure an applied force or soils' load-bearing capacity (Ghildyal and Tripathi, 1987). Though few attempts had been taken to evaluate the shear strength (Rathnaweera, et al., 2010), no attempt had been made to estimate the compression strength of lowland puddled soils in Sri Lanka.

An indirect and in-situ method for assessing soil strength is to use a penetrometer which gives quantitative reading on penetration resistance (PR). PR is not soil strength but a composite parameter which could be related to the soil strength (Hillel, 2004). Though this relationship has not been defined yet, PR values are used for engineering applications due to its easiness and simplicity in measurement (Hillel, 2004).However it is not adequate for accurate assessment of soil strength (Lipiec and Hatano, 2003) because assessing by one direct index may mislead the results (Campbell and Henshall, 1991).On the other hand, PR

\footnotetext{
Department of Agricultural Engineering, Faculty of Agriculture, University of Peradeniya, Sri Lanka

2 University Sub Campus, Faculty of Agriculture, University of Peradeniya, Mahailluppallama

Corresponding Author: gvtvw@yahoo.com
} 
gives relatively great spatial variation due to point measurement (Lipiec and Hatano, 2003). Hence, Glinski and Lipiec, (1990) suggested to conduct further studies to develop relationship between PR and non-point (bulk) soil parameters. Soil factors including soil moisture content, bulk density, soil compressibility, soil structure, soil texture and organic matter content are the potential non-point soil parameters (IRRI, 1994).

Hence, this study was aimed to estimate the overall PR of lowland puddled soils of Sri Lanka through the assessment of bulk soil parameters. The specific objectives of this study were to (1) measure variation of soil PR and potential bulk soil parameters under real field condition (2) identify the suitable determinant to explain the PR variation and (3) build up their relationships. It was hypothesized that these significant relationships could be utilized to asses overall PR of the puddled soils.

Considering available laboratory facilities and the measurability, soil parameters including soil moisture content (MC), bulk density (BD), particle density (PD), porosity (PO), soil texture and organic matter content $(\mathrm{OM})$ were considered for this study.

\section{METHODOLOGY}

This experiment was conducted in the research farm of Faculty of Agriculture, Rajarata University of Sri Lanka, Puliyankulama, Anuradhapura which belongs to $\mathrm{DL}_{1 \mathrm{~b}}$ agro ecological region (Punyawardane et al., 2003) during the 2013/14 "Maha" season. Reddish Brown Earths and Low Humic Gley soils are the major soil types and Madawachiya series is the dominant soil series found in this area (Mapa, et al., 2009).

\section{Field preparation and crop establishment}

A paddy field with Low Humic Gley soil was selected as the experimental site. Land preparation was done after impounding water with two ploughings up to $30 \mathrm{~cm}$ by fourwheel tractor coupled disk plough and tine tiller, respectively. Harrowing, fine levelling and puddling were done by two-wheel tractor coupled rotovator and levelling board. Basel fertilizer was added just before the levelling as the Department of Agriculture (DOA) recommendation. Plots were demarcated by placing drainage channels. Wooden pegs were used to establish grid system $\left(1 \times 1 \mathrm{~m}^{2}\right)$ which helps to identify the proper sampling place avoiding overlapping of sampling.

Four treatments namely; $\mathrm{T}_{1}-$ Control (bare land), $\mathrm{T}_{2}-$ Paddy field with no weed control, $\mathrm{T}_{3}$ - Paddy field with chemical weed control, and $\mathrm{T}_{4}$ - Paddy field with manual weed control by modified Asakura wooden clog (Jayatissa and Wickramasinghe, 2010) with three replicates were established in 12 plots of $8 \times 5 \mathrm{~m}^{2}$ as the Randomized Complete Block Design (RCBD).

Two weeks age seedlings of $\mathrm{Bg} 358$ (SAMBA) 3.5 months variety in wet-bed nursery were established with spacing of $12.5 \mathrm{~cm}$ x $24 \mathrm{~cm}$ as discussed by Jayatissa and Wickramasinghe (2010) to facilitate the use of modified Asakura wooden clog in $T_{4}$, maintaining the recommended plant density. After the establishment, the irrigation and fertilizer applications were done as per the DOA recommendation. 


\section{Field measurement and sampling}

Field measurement and sampling were done from plant establishment to harvest (until 15 weeks after transplanting (WAT)) with one week sampling interval. ASAE standard S313.2 (AEAE, 1994) was followed to measure PR using Eijkelkamp hand penetrometer at different depths from 0 to $30 \mathrm{~cm}$ with $5 \mathrm{~cm}$ depth intervals (Seven readings/plot).

Disturbed and undisturbed soil samples (six samples / plot) were collected representing three layers; $0-10 \mathrm{~cm}, 10-20 \mathrm{~cm}$ and $20-30 \mathrm{~cm}$ using soil auger and core sampler, respectively.

\section{Laboratory analysis}

Standard soil physical and chemical analyses were conducted. Soil MC was determined by gravimetric method (Majumdar and Singh, 2002). The core sampler $(\varnothing=50 \mathrm{~mm})$ was used to determine the BD of the soil (Singh, 1980). As discussed by Majumdar and singh in 2002, PD was determined using pycnometer method and PO was calculated. As discussed by Dharmakeerthi (2007), soil texture was determined by pipette method. As stated by Wickramasinghe (2007), OM content was determined by Walkly and Black wet oxidation method with the empirical factor 2 for the carbon-OM conversion (Nelson and Sommers, 1982).

\section{Data analysis}

Significant variables at 0.05 level of significance $(\alpha)$ was selected by fitting analysis of variance (ANOVA) models using GLM procedure of SAS software. Least Square Mean (LSMEANS) separation was used to separate means of significant variables. Relationships between PR and bulk soil parameters were identified by fitting linear regression models.

\section{RESULTS AND DISCUSSION}

Table 1 and 2 summarise the LSMEAN separation and regression statistics of soil properties, respectively. The temporal variations of the soil properties are illustrated in Fig. 1.

\section{Soil properties}

Penetration Resistance (PR) significantly varied with weed controlling method (treatment), soil depth and the time (WAT) at $0.05 \alpha$ level. Reference to the treatment variation, the significantly highest $\mathrm{PR}$ value $(1053.20 \mathrm{kPa})$ was recorded in $\mathrm{T}_{4}$ and there were no significant difference among other treatments. This may be due to the relatively higher soil compaction due to wooden clog application in $\mathrm{T}_{4}$. PR significantly increased with the depth of the soil from $496.59 \mathrm{kPa}$ to $1635.40 \mathrm{kPa}$. While considering the temporal variation, PR increased with time from lowest at puddling $(151.28 \mathrm{kPa})$ to highest at 6 WAT $(1364.45 \mathrm{kPa})$ Then, it decreased little upto 8 WAT and remained constant till 14 WAT. Then, it increased at harvesting (15 WAT). As reported by Bhagat, (2003) this is due to the MC variation which showed the highest significant correlation (correlation coefficient / $r=-0.715$ ) with PR.The lowest PR was recorded at puddling due to higher MC and loose arrangement of soil particles and then it increased as soil particles settled, which is in agreement with Bhagat, (2003). 
Moisture content (MC) of the experimental site significantly varied with irrigation pattern and rainfall. In addition, MC varied with the weed controlling method, soil depth and time (WAT) at $0.05 \alpha$ level. Significantly highest $(23.61 \%)$ and lowest $(21.31 \%)$ MC was recorded in $\mathrm{T}_{3}$ where chemical weed control was practiced and $\mathrm{T}_{4}$ where weed controlled by wooden log was practiced, respectively. However, they were not significantly different from other treatments. This may due to the higher evaporating rate of $\mathrm{T}_{4}$ due to frequent disturbance of surface soil while applying wooden clogs. MC ranged from $18.03 \%$ to $27.40 \%$ through the depth by showing significant inverse relationship. This may be due to the supplementary surface irrigation at particular intervals. Supplied irrigation water may be absorbed by surface layers which contain higher OM and limited percolation might have occurred. As shown in Fig. 1, the highest MC (30.87\%) was recorded initially (1 WAT) and it declined up to a certain level and showed slight variation with the irrigation pattern and rainfall. After 10 weeks, irrigation supply was cut down and the field was prepared for harvesting. Hence the lowest MC was recorded at 12 WAT (12.03\%). However a sudden increment of MC was noted at 13 - 14 WAT due to additional irrigation water supply. After 14 WAT, field was prepared for the harvesting by cutting the irrigation water supply again. This showed the significantly highest correlation $(r=-0.893)$ with BD.

Bulk density (BD) of the soil was significantly affected by the weed controlling method, soil depth and the time (WAT) at $0.05 \alpha$ level. It varied from $1.58 \mathrm{~g} / \mathrm{cm}^{3}-1.67 \mathrm{~g} / \mathrm{cm}$ among treatments. Significantly lowest BD was recorded in $\mathrm{T}_{3}$ where chemical weed controlling was practiced and highest in $\mathrm{T}_{4}$ where wooden clog was applied, which was not significantly different from other treatments. This may be due to the soil dispersion by chemicals. BD varied with depth showing significantly direct relationship and ranging from $1.45 \mathrm{~g} / \mathrm{cm}^{3}$ to $1.78 \mathrm{~g} / \mathrm{cm}^{3}$.As demonstrated in Fig. 1, BD was varied throughout the experimental period. As explained by Bhagat (2003) initially lowest BD $\left(1.62 \mathrm{~g} / \mathrm{cm}^{2}\right.$ at $\left.1 \mathrm{WAT}\right)$ was due to the submergence prior to tillage and it increased with time up to $1.81 \mathrm{~g} / \mathrm{cm}^{2}(12 \mathrm{WAT})$ which recorded as the highest, when the puddled soils undergo desiccation because of soil shrinkage. As reported by Eudoxie, et al. (2012), this may be due to the MC variation of the field which showed the highest significant correlation $(r=-0.893)$.

Particle density (PD) of the soil was not significantly affected by weed controlling pattern or soil depth or time (WAT) at $0.05 \alpha$ level. Average PD was noted as $2.55 \mathrm{~g} / \mathrm{cm}^{3}$ which is closer to PD of most mineral constituents as reported by Majumdear and Singh (2002).

Soil Porosity (PO) also significantly varied with the weed controlling pattern, depth of the soil and the time (WAT) at $0.05 \alpha$ level. The significantly highest and lowest PO values were observed in $\mathrm{T}_{3}(37.24 \%)$ and $\mathrm{T}_{4}(33.74 \%)$, respectively. Though $\mathrm{T}_{1}$ and $\mathrm{T}_{2}$ were not significantly different, $T_{1}$ was significantly different from $T_{4}$ and $T_{2}$ from $T_{3}$. This is inverse reaction of $\mathrm{BD}$ due to the soil dispersion by chemicals. $\mathrm{PO}$ was significantly and inversely proportional to the depth of the soil ranging from $29.61 \%$ to $42.65 \%$. This may be due to the bulk density variation of the earth. As shown in Fig. 1, at the puddling (1 WAT), higher PO value $(4.43 \%)$ was observed temporally, then sudden decline was noted. Similar findings were reported in many studies (Bhagat, 2003). The lowest PO (27.975\%) was recorded at 12 WAT. Rest of the period showed similar PO values with small variations. This may be due to the BD variation which showed significantly highest correlation $(r=-0.790)$.

By comparing the textural behaviour between starting (1 WAT) and end (15 WAT) of this experiment, only clay content showed a significant deference. While sand content varied with weed controlling pattern, clay content varied with weed controlling pattern and soil depth instead of the temporal variation. Sand \% varied significantly from $73.76 \%$ in $\mathrm{T}_{3}$ to 
$86.18 \%$ in $\mathrm{T}_{1}$. However there were no significant differences among, $\mathrm{T}_{2}, \mathrm{~T}_{3}$ or $\mathrm{T}_{4}$ and between $\mathrm{T}_{1}$ and $\mathrm{T}_{4}$. Average sand content in different depths was $78.98 \%$. Average silt content was $7.54 \%$. Clay content significantly varied in each treatment as $\mathrm{T}_{4}<\mathrm{T}_{1}<\mathrm{T}_{2}<\mathrm{T}_{3}$ ranging from $2.92 \%$ to $22.08 \%$. Significantly highest clay accumulation; $14.56 \%$ was recorded in $20-30 \mathrm{~cm}$ layer, while surface layer had the lowest clay content $(11.10 \%)$. There was no significant difference in clay content in two shallow layers.

Treatment or temporal effect did not significantly affect to the OM in the soil and average OM was $0.8 \%$. As reported by Jayatissa and Wickramasinghe (2010) there should be an increase in $\mathrm{OM}$ in $\mathrm{T}_{4}$ where the wooden clog was applied due to weed burring. But, observed time (15 weeks) is not sufficient to reflect that OM increment due to buried weeds. However, OM showed significantly negative relationship with the depth of the soil ranging from $0.567 \%$ to $0.921 \%$. This is due higher accumulation of OM in surface layers than that of the deep layers and as reported by Nayanaka et al. (2010) and Eudoxie, et al. (2012).

Table 1. LSMEAN for soil properties

\begin{tabular}{|c|c|c|c|c|c|c|c|}
\hline \multirow{2}{*}{ Factor } & \multicolumn{4}{|c|}{ Treatments } & \multicolumn{3}{|c|}{ Depth Layers } \\
\hline & $\overline{\mathrm{T}_{1}}$ & $\mathrm{~T}_{2}$ & $\mathrm{~T}_{3}$ & $\overline{\mathrm{T}_{4}}$ & 01 & 02 & 03 \\
\hline$\overline{\mathrm{PR}(\mathrm{kPa})}$ & $955.11^{\mathrm{b}}$ & $883.92^{\mathrm{b}}$ & $888.10^{\mathrm{b}}$ & $1053.2^{\mathrm{a}}$ & $496.59^{q}$ & $685.39^{r}$ & $1635.4^{\mathrm{p}}$ \\
\hline $\mathrm{MC} \%$ & $22.303^{\mathrm{ab}}$ & $22.211^{\mathrm{ab}}$ & $23.612^{\mathrm{a}}$ & $21.307^{\mathrm{b}}$ & $27.396^{\mathrm{p}}$ & $21.652^{q}$ & $18.030^{\mathrm{r}}$ \\
\hline $\mathrm{BD}\left(\mathrm{g} / \mathrm{cm}^{3}\right)$ & $1.635^{\mathrm{a}}$ & $1.631^{\mathrm{a}}$ & $1.579^{\mathrm{b}}$ & $1.670^{\mathrm{a}}$ & $1.450^{\mathrm{r}}$ & $1.655^{\mathrm{q}}$ & $1.782^{\mathrm{p}}$ \\
\hline $\mathrm{PD}\left(\mathrm{g} / \mathrm{cm}^{3}\right)$ & $2.546^{\mathrm{a}}$ & $2.533^{\mathrm{a}}$ & $2.526^{\mathrm{a}}$ & $2.526^{\mathrm{a}}$ & $2.533^{\mathrm{p}}$ & $2.528^{\mathrm{p}}$ & $2.537^{\mathrm{p}}$ \\
\hline $\mathrm{PO} \%$ & $35.714^{\mathrm{ab}}$ & $35.352^{\mathrm{bc}}$ & $37.241^{\mathrm{a}}$ & $33.735^{\mathrm{c}}$ & $42.650^{\mathrm{p}}$ & $34.269^{q}$ & $29.613^{r}$ \\
\hline Sand $\%$ & $86.176^{\mathrm{a}}$ & $76.320^{\mathrm{b}}$ & $73.764^{b}$ & $79.667^{\mathrm{ab}}$ & $80.616^{\mathrm{p}}$ & $78.865^{\mathrm{p}}$ & $77.464^{\mathrm{p}}$ \\
\hline Silt $\%$ & $7.708^{\mathrm{a}}$ & $8.338^{\mathrm{a}}$ & $7.724^{\mathrm{a}}$ & $6.400^{\mathrm{a}}$ & $9.923^{\mathrm{p}}$ & $6.772^{\mathrm{p}}$ & $5.932^{\mathrm{p}}$ \\
\hline Clay \% & $9.168^{\mathrm{c}}$ & $15.691^{\mathrm{b}}$ & $22.078^{\mathrm{a}}$ & $2.918^{\mathrm{d}}$ & $11.097^{\mathrm{q}}$ & $11.731^{\mathrm{q}}$ & $14.563^{\mathrm{P}}$ \\
\hline $\mathrm{OM} \%$ & $0.796^{\mathrm{a}}$ & $0.710^{\mathrm{a}}$ & $0.815^{\mathrm{a}}$ & $0.861^{\mathrm{a}}$ & $0.921^{\mathrm{p}}$ & $0.898^{\mathrm{p}}$ & $0.567^{\mathrm{q}}$ \\
\hline
\end{tabular}

Means with the same letter are not significantly different at $0.05 \alpha$ level

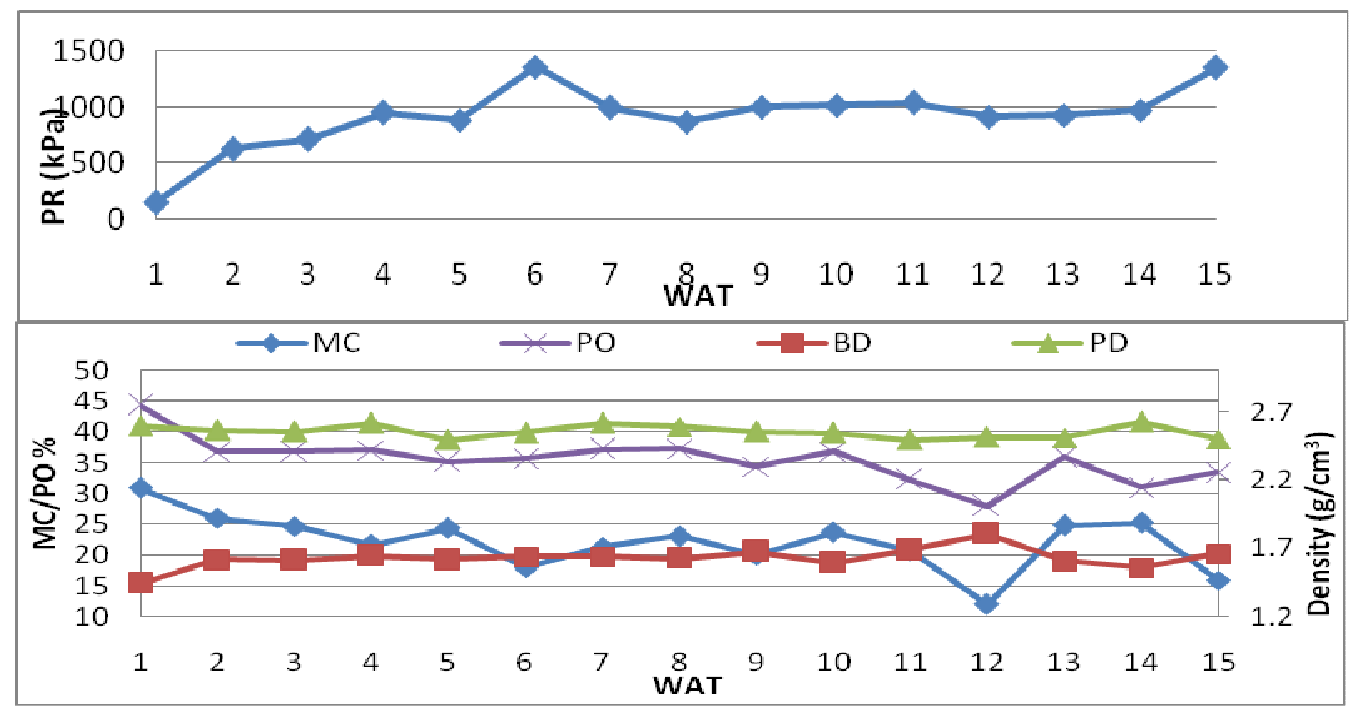

Fig. 1. Temporal variation of soil properties 


\section{Relationship between PR and other soil properties}

As per the regression analysis results in Table 02 , BD and $\mathrm{MC}$ are significantly related with PR in layer one $(0-10 \mathrm{~cm})$ and PO shows significant relationship with PR in layers $2(10$ $20 \mathrm{~cm})$ and $3(20-30 \mathrm{~cm})$ at $0.05 \alpha$ level. As reported by Eudoxie, et al. (2012), only moisture content shows significant relationship with soil strength of upland soils. This is partially supportive finding to this result. However surface shear strength was evaluated in that study.

Table. 2. Regression statistics soil properties

\begin{tabular}{cccc}
\hline Soil Layer & P Value & Equation & R-square \\
\hline 01 & $<0.0001$ & $4017.865-44.719 \mathrm{MC}-1669.825 \mathrm{BD}$ & 0.8332 \\
02 & 0.0004 & $2115.648-44.184 \mathrm{PO}$ & 0.4405 \\
03 & 0.0142 & $3383.779-58.094 \mathrm{PO}$ & 0.2439 \\
\hline
\end{tabular}

\section{CONCLUSION}

Measured PR and bulk soil properties except PD varied with weed controlling pattern and depth of the soil temporally. Bulk density and moisture content could be utilized to determine the overall PR in surface layer $(0-10 \mathrm{~cm})$ by $4017.865-44.719 \mathrm{MC}-1669.825$ BD. Porosity could be utilized to determine the overall PR at $2^{\text {nd }}$ layer $(10-20 \mathrm{~cm})$ and $3^{\text {r.d }}$ layer $(20-30 \mathrm{~cm})$ by $2115.648-44.184 \mathrm{PO}$ and $3383.779-58.094 \mathrm{PO}$, respectively.

It is suggested to conduct future studies including weed and plant growth parameters which may provide sound information to improve this finding.

\section{ACKNOWLEDGEMENT}

The authors thank the Rajarata University of Sri Lanka (RUSL) and University of Peradeniya for providing the opportunity to make this research project a success and Mr. S.A.S.M. Thilakasiri for the assistance in experimental activities. This research work was funded by University Grants Commission (UGC), Sri Lanka.

\section{REFERENCES}

ASAE. (1994). ASAE Standards 1994. $14^{\text {th }}$ Edition, ASAE, USA.

Bhagat, R.M. (2003). Rice Lands of South and South East Asia, Some Soil Physical Aspects. Department of Soil Science, CSKHPAU, Palampur, H.P., India. [on line] [Accessed on 28.07.2014] available at: http://users.ictp.it/ pub_off/ lectures/lns018/07Bhagat1.pdf

Campbell, D.J. and Henshall, .J.K. (1991). Bulk Density in Soil Analysis, Physical Methods, In: K. A. Smith and C. E. Mullins, (Ed.). Marcel Dekker, New York, pp. 329-366. 
Dharmakeerthi, R.S. (2007). Manual of Soil Sampling and Analysis. Pp. 19 - 21. In: Dharmakeerthi, R.S., Indraratne, S.P. and Kumarage, D. (Ed). Special Publication No. 01, Soil Science Society of Sri Lanka.

Eudoxie, G. D., Phillips, D. and Springer, R. (2012). Surface Hardness as an Indicator of Soil Strength of Agricultural Soils. Open Journal of Soil Science, 2012, 2, 341-346. doi.org/10.4236/ojss.2012.24040.

Ghildyal, B.P. and Tripathi, R.P. (1987). Soil Physics. Johan Wiley Eastern Limited, New Delhi, India.

Glinski J.,and Lipiec, J. (1990). Soil Physical Conditions and Plant Roots. CRC Press, Boca Raton.

Hillel, D. (2004). Introduction to Environmental Soil Physics. Elsevier, USA.

IRRI. (1994). Soil Physical Properties Measurement and Use in Rice-based Cropping systems. Pp 59 - 65. In: Wopereis, M., Kropff, M., Boama, J., Van Wijk, A. and Woodhead, T. (Ed). International Rice Research Institute, Manila, Philippines.

Jayatissa, D.N. and Wickramasinghe, W.A.M.P. (2010). Final report on Testing Improved Wooden Clog for Weed Control in Row-seeded or Row-planted Paddy Fields, Report submitted to JICA/EAA.

Lipiec, J. and Hatano, R. (2003). Quantification of Compaction Effects on Soil Physical Properties and Crop Growth. Geoderma, Vol. 116, No. 1-2, 107-136. doi:10.1016/S00167061(03) 00097-1.

Majumbar, S.P. and Singh, R.A. (2002). Analysis of Soil Physical Properties. Agrobios (India), Jodhpur.

Mapa, R.B., Somasiri, S. and Dassanayake, A.R. (2009). Soils of the Dry Zone of Sri Lanka. Morphology, Characterization and Classification. Special Publication No. 7. Soil ScienceSociety of Sri Lanka. Survodaya Vishva Lekha, Colombo, Sri Lanka.

Nayanaka, V.G.D., Vitharana, W.A.U. and Mapa, R.B. (2010). Geostatistical Analysis of Soil Properties to Support Spatial Sampling in a Paddy Growing Alfisol. Tropical Agricultural Research Vol. 22 (1), pp.34 - 44

Nelson, D.W. and Sommers, L.E. (1982). Total carbon, organic carbon and organic matter. In Methods of soil analysis. Part 2. $2^{\text {nd }}$ ed. Agronomy No.09, American Society of Agronomy, Madison, WI, USA.

Punyawardane, B.V.R., Bandara, T.M.J., Munasinghe, M.A.K., Banda, N.J. and Pushpakumara, S.M.V. (2003). Agro-ecological Regions of Sri Lanka. Natural Resource Management Center, Department of Agriculture, Peradeniya, Sri Lanka.

Rathnaweera, A.C., Rajapakse, N.N., Ranasinghe, C.J., Thennakooon, T.M.S., Kumara, R.S., Balasooriya, C.P. and Bandara, M.A. (2010). Design of Power Weeder for Low Land Paddy Cultivation. In the International Conference on Sustainable Built Environment, Kandy, 13 14 December, 2010. 
Singh, R.A. (1980). Soil physical analysis. Kalyani publishers, New Delhi.

Wickramasinghe, W.M.A.D.B. (2007). Manual of Soil Sampling and Analysis. pp. 59 - 60. In: Dharmakeerthi, R.S., Indraratne, S.P. and Kumarage, D. (Ed). Special Publication No. 01, Soil Science Society of Sri Lanka. 